\title{
Attitude and knowledge of isolation in operative field among undergraduate dental students
}

\author{
Fuad Abdo Al-Sabri ${ }^{1,2}$, Ahmed Mohamed Elmarakby ${ }^{1,3}$, Ahmed Mohammed Hassan ${ }^{1,3}$
}

Correspondence: Dr. Ahmed Mohammed Hassan

Email: ahmed.altabbakh@yahoo.com

\begin{abstract}
'Department of Restorative Dental Sciences, Al-Farabi Dental College, Riyadh, KSA, 2Department of Operative Dentistry, Faculty of Dentistry, Thamar University, Dhamar, Yemen, ${ }^{3}$ Department of Operative Dentistry, Faculty of Dentistry, Al-Azhar University, Cairo, Egypt
\end{abstract}

\section{ABSTRACT}

Objective: The purpose of this study was to evaluate the general attitude of undergraduate dental students toward rubber dam use, specifically focusing on operative procedures before starting to serve community. Methods: Questionnaires were distributed to undergraduate clinical years' students of two private colleges; Al-Farabi Dental College, Riyadh, KSA and Buraidah Private Colleges, Qassim, KSA. Questions were asked about areas where the students used rubber dam in operative procedures, in which types of caries classes, and in which type of restoration they frequently used the rubber dam. Results: We found that students of both private dental colleges agreed with the opinions that proper isolation cannot be achieved for the restoration of operative procedures without using rubber dam and restoration placed under rubber dam have a greater longevity than those placed without. Conclusions: Within the limitations of the present study, it can be concluded that the perceptions of dental students on rubber dam need to be improved and strategies should be developed so that this valuable adjunct will comprise one of the indispensable elements of dental care.

Key words: Isolation, operative dentistry, rubber dam

\section{INTRODUCTION}

Rubber dam is universally acknowledged as a mandatory adjunct, particularly during endodontic treatment. Many authors advocate its usage and encourage practitioners to adopt it in routine practice including operative dentistry field. ${ }^{[1]}$ Rubber dam offers the practitioners with a wide variety of advantages such as isolation of the operative area, provision of aseptic field, improving infection control, preventing ingestion or aspiration of burs or instruments, as well as protection and retraction of soft tissue..$^{[2-5]}$ Other advantage is increased patient comfort with a positive opinion about rubber dam application. ${ }^{[6]}$

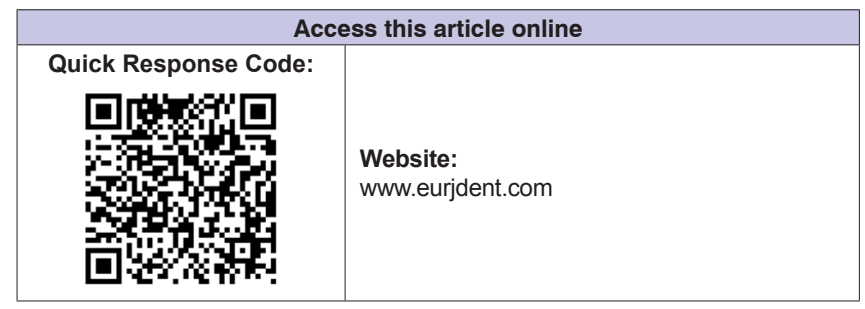

Operative dentistry field is a major area where rubber dam is used. ${ }^{[7]}$ Moreover, rubber dam use should be reevaluated from a medicolegal point of view, considering an increase in malpractices, directed against general practitioners. Failure to use rubber dam has been described as a serious departure from the standard of care. ${ }^{[8]}$

With all these advantages as well as the legal aspects favoring rubber dam, but many practitioners still resist its use in routine care. They claim that it is time consuming and uncomfortable for

This is an open access article distributed under the terms of the Creative Commons Attribution-NonCommercial-ShareAlike 3.0 License, which allows others to remix, tweak, and build upon the work non-commercially, as long as the author is credited and the new creations are licensed under the identical terms.

For reprints contact: reprints@medknow.com

How to cite this article: Al-Sabri FA, Elmarakby AM, Hassan AM. Attitude and knowledge of isolation in operative field among undergraduate dental students. Eur J Dent 2017;11:83-8.

DOI: 10.4103/ejd.ejd_191_16 
the patients. ${ }^{[9-14]}$ Training on rubber dam application has been considered as an integral part of the contemporary dental education. Many dental schools advocate the use of rubber dam by their students from the first meeting with the patient. ${ }^{[2]}$

Since surveys among dental students are helpful tools to draw the outline of the future dental workforce, so investigating dental students' perceptions and attitudes toward rubber dam use will contribute to underlining the inherent problems related with the implementation of this worldwide acknowledged methodology. Depending on the results, strategies can be developed to enhance the way of contemporary, and high-quality aspects of clinical dentistry are delivered and instilled.

The purpose of the present study was to determine the general attitude of Saudi dental students' groups enrolled in two different private colleges toward rubber dam application, specifically focusing on operative field treatment and evaluates the problems they encounter related with this tool.

\section{METHODS}

Anonymous survey questionnaires were distributed to undergraduate clinical students enrolled in two private dental colleges in Saudi Arabia; (a) Al-Farabi Private College, Riyadh, KSA and (b) Buraidah Private Colleges, Qassim, KSA. Before the study, anonymity of the respondents was confirmed. A total of 294 survey forms were printed and delivered to the students. Two hundred copies were directed to the undergraduate clinical years' students (A) and 94 copies (B). The students were not held obliged to return the forms. In the questionnaire, students were asked about areas of dental practice in operative field where they used rubber dam. The survey continued with questions regarding students' opinion about rubber dam's advantages as well as difficulties. They were asked if they agreed or disagreed with certain aspects of rubber dam and whether they use it because they believe that the restorations placed under rubber dam have a greater longevity or not. They were also asked whether they frequently use the rubber dam for isolation in maxillary anterior Class $V$ restoration or just they isolate using the cotton roll. They were asked if they integrate rubber dam as a mandatory tool in both adults and children and during which procedures or cavity type, they will plan to use it. The printed questionnaires were delivered to the students at the beginning of the practical session and collected back at the end of the session with respond rate of $100 \%$.

Statistical analysis was performed using Number Cruncher Statistical System 2007 Statistical Software (Utah, USA) pocket program. In addition to descriptive statistical methods, Chi-square test was used for the comparison of qualitative data. Results were evaluated at a significance level of $P<0.05$.

\section{RESULTS}

The final results were summarized in Tables 1 and 2 and illustrated in Figures 1 and 2. The majority of the students of both colleges responded negatively to use rubber dam for children (96.59\%). On the other hand, most of them confirmed the use of rubber dam with adult patients in restorative procedures (97.61). Application of rubber dam in posterior esthetic restoration was highly recommended by the students of both colleges, while this is not true regarding amalgam. Regarding anterior restorations, the students of both colleges advocate the use of rubber dam, with a higher percentage for resin composite comparing with glass ionomer cement.

Regarding preclinical training, most of the school A students believed they received satisfactory education regarding rubber dam usage, whereas only two-thirds of school B students agreed with that opinion. This difference in response was statistically significant $(P<0.05)$, also there is a significant difference regarding the use of rubber dam in maxillary anterior Class $V$ with a higher percentage for school A compared to school B students.

Most students agreed with the opinion that operative procedures and treatments performed using the rubber dam were more successful in both cavity preparation and restorative material properties than those where it was not used. Not only the students shared the opinion that proper isolation cannot be

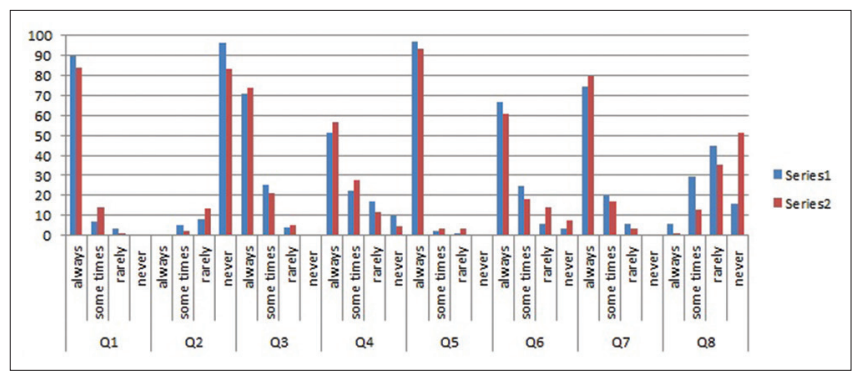

Figure 1: Bar chart showing the percentage of answers given by students to questions regarding utilization of rubber dam 


\begin{tabular}{|c|c|c|}
\hline Questions & School A, $n(\%)$ & School B, $n(\%)$ \\
\hline \multicolumn{3}{|c|}{ Q1. Do you use rubber dam on adult? } \\
\hline Always & $180(90)$ & $80(84.10)$ \\
\hline Sometimes & $14(7)$ & $13(14)$ \\
\hline Rarely & $6(3)$ & $1(1.20)$ \\
\hline Never & 0 & 0 \\
\hline \multicolumn{3}{|c|}{ Q2. Do you use rubber dam on child? } \\
\hline Always & 0 & 0 \\
\hline Sometimes & $8(5)$ & $2(2.40)$ \\
\hline Rarely & $12(7.8)$ & $11(13.55)$ \\
\hline Never & $180(96.2)$ & $81(83.15)$ \\
\hline \multicolumn{3}{|c|}{ Q3. Do you use the rubber dam during operative procedures for anterior composite? } \\
\hline Always & $142(71)$ & $69(73.55)$ \\
\hline Sometimes & $50(25)$ & $20(21.25)$ \\
\hline Rarely & $8(4)$ & $5(5.20)$ \\
\hline Never & 0 & 0 \\
\hline \multicolumn{3}{|c|}{ Q4. Do you use the rubber dam during operative procedures for anterior glass ionomer? } \\
\hline Always & $102(51)$ & $53(56.38)$ \\
\hline Sometimes & $44(22)$ & $26(27.65)$ \\
\hline Rarely & $34(17)$ & $11(11.70)$ \\
\hline Never & $20(10)$ & $4(4.20)$ \\
\hline \multicolumn{3}{|c|}{ Q5. Do you use the rubber dam during operative procedures for posterior composite? } \\
\hline Always & $194(97)$ & $88(93.61)$ \\
\hline Sometimes & $4(2)$ & $3(3.19)$ \\
\hline Rarely & $2(1)$ & $3(3.19)$ \\
\hline Never & 0 & 0 \\
\hline \multicolumn{3}{|c|}{ Q6. Do you use the rubber dam during operative procedures for posterior glass ionomer? } \\
\hline Always & $133(66.50)$ & $57(60.63)$ \\
\hline Sometimes & $49(24.5)$ & $17(18.08)$ \\
\hline Rarely & $11(5.5)$ & $13(82)$ \\
\hline Never & $7(3.5)$ & $7(7.44)$ \\
\hline \multicolumn{3}{|c|}{ Q7. Do you use the rubber dam during operative procedures for posterior compomer? } \\
\hline Always & $149(74.5)$ & $75(79.78)$ \\
\hline Sometimes & $40(20)$ & $16(17.02)$ \\
\hline Rarely & $11(5.5)$ & $3(3.19)$ \\
\hline Never & 0 & 0 \\
\hline \multicolumn{3}{|c|}{ Q8. Do you use the rubber dam during operative procedures for posterior amalgam? } \\
\hline Always & $11(5.50)$ & $1(1.06)$ \\
\hline Sometimes & $59(29.50)$ & $12(12.76)$ \\
\hline Rarely & $99(45)$ & $33(35.10)$ \\
\hline Never & $31(15.50)$ & $48(51.06)$ \\
\hline
\end{tabular}

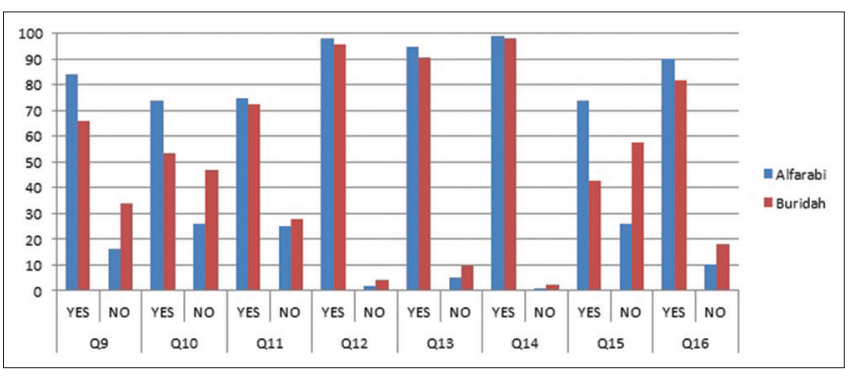

Figure 2: Bar chart showing the percentage of answers given by students to questions regarding attitude of students to the use of rubber dam achieved for the operative field without using rubber dam, but also they shared the opinion that restorations placed under rubber dam have a greater longevity than those placed without. On the other hand, more than one-half of school B disagreed with the opinion that rubber dam use would give good visibility and enables clearer access during both cavity preparation and placing restoration, whereas only one-quarter of school A students adopt this opinion. This difference was statistically significant $(P<0.05)$. There was an agreement between the two dental colleges' student 


\begin{tabular}{|c|c|c|}
\hline Questions & School A, $n(\%)$ & School B, $n(\%)$ \\
\hline \multicolumn{3}{|c|}{ Q9: Did you receive training in rubber dam placement during your preclinical studies? } \\
\hline Yes & $168(84)$ & $62(65.95)$ \\
\hline No & $32(16)$ & $32(34.05)$ \\
\hline \multicolumn{3}{|c|}{$\begin{array}{l}\text { Q10. Do you frequently use the rubber dam for isolation in maxillary anterior class } V \text { restoration or just } \\
\text { isolate using the cotton roll? }\end{array}$} \\
\hline Yes & $148(74)$ & $50(53.19)$ \\
\hline No & $52(26)$ & $44(46.81)$ \\
\hline \multicolumn{3}{|c|}{$\begin{array}{l}\text { Q11. Did operative procedures in posterior teeth and treatment perform using the rubber dam was more } \\
\text { successful in both cavity preparation and restorative material properties than those where it was not used? }\end{array}$} \\
\hline Yes & $150(75)$ & $68(72.34)$ \\
\hline No & $50(25)$ & $26(27.65)$ \\
\hline \multicolumn{3}{|c|}{$\begin{array}{l}\text { Q12. Do you agree that proper isolation cannot be achieved for restoration of operative procedures } \\
\text { without rubber dam }\end{array}$} \\
\hline Yes & $196(98)$ & $90(95.74)$ \\
\hline No & $4(2)$ & $4(4.26)$ \\
\hline \multicolumn{3}{|c|}{ Q13. Do you agree that patient do not like rubber dam } \\
\hline Yes & $190(95)$ & $85(90.42)$ \\
\hline No & $10(5)$ & $9(9.57)$ \\
\hline \multicolumn{3}{|c|}{$\begin{array}{l}\text { Q14. Do you agree that restorations placed under rubber dam have a greater longevity than those } \\
\text { placed without }\end{array}$} \\
\hline Yes & $198(99)$ & $92(97.87)$ \\
\hline No & $2(1)$ & $2(2.13)$ \\
\hline \multicolumn{3}{|c|}{$\begin{array}{l}\text { Q15. Do you agree that rubber dam use would give good visibility and enables clearer access during } \\
\text { both cavity preparation and placing restoration }\end{array}$} \\
\hline Yes & $148(74)$ & $40(42.55)$ \\
\hline No & $52(26)$ & $54(57.45)$ \\
\hline \multicolumn{3}{|c|}{ Q16. Do you agree that rubber dam is difficult to apply } \\
\hline Yes & $180(90)$ & $77(81.91)$ \\
\hline No & $20(10)$ & $17(18.09)$ \\
\hline
\end{tabular}

for the opinion that application of the dam was difficult and patients dislike it.

In spite of the agreement of the students of both colleges that adequate isolation cannot be achieved without rubber dam, there was a significant difference $(P<0.05)$ between the two colleges with a higher percentage to Al-Farabi College compared to Buraidah College. On the other hand, more than one-half of the students of Buraidah College disagreed with the opinion that rubber dam use would give good visibility and enables clearer access during both cavity preparation and placing restoration contrary to the student of Al-Farabi College who believe in this opinion. This difference between the two colleges was statistically significant $(P<0.05)$. No statistically significant differences were determined between the two colleges in terms of the other evaluated parameters $(P>0.05)$.

\section{DISCUSSION}

There is no doubt that rubber dam is generally preferred during endodontics, but its usefulness during restorative treatment cannot be overlooked. The present study basically directed toward the use of rubber dam in operative procedures as the use of rubber dam in operative procedures is still questionable.

This survey was conducted on undergraduate students as they seem to give more honest answers compared to the general practitioners who subjected to the stress of challenging environment. This is in accordance with Hill and Rubel. ${ }^{[15]}$ Most of the dental schools emphasize the importance of rubber dam application, especially during endodontic and adhesive procedures. ${ }^{[16]}$ In spite of the undoubted advantages of rubber dam, it is still believed to be controversy issue among general practitioners. ${ }^{[17]}$ The results obtained from this study support this hypothesis. Moreover, the trend of these two dental colleges to stress on the usage of rubber dam in endodontic field rather than operative field may positively affect this finding. In addition, extended treatment period, patients dislike, and decreased clear access during both cavity preparation and placing restoration also considered as disadvantages that 
may decrease the use of rubber dam. This strongly supported by Whitworth et al. who found the majority of UK dentists never used the rubber dam for both endodontics and operative procedures. ${ }^{[12]}$

In our study, the percentage of routine uses of rubber dam for adult patient was $90 \%$ and $84 \%$ for the students of Al-Farabi and Buraidah, respectively. This result is in disagreement with Unal et al. ${ }^{[18]}$ who found only $5.1 \%$ of Turkish general practitioners use rubber dam. Furthermore, Peciuliene et al. and Slaus and Bottenberg found that two-thirds of the general practitioner do not use rubber dam. ${ }^{[19,20]}$ Hill and Rubel related the low percentage of general practitioners using rubber dam to the inconvenience and their belief it is unnecessary. ${ }^{[15]}$ To overcome this opinion, the role of rubber dam plays in safety measures during dental care can be further emphasized by showing complications arising from lack of usage.

On the other hand, another study supported our result as he found the high percentage of American general practitioners use rubber dam. ${ }^{[21]}$ They refer this result to the strict malpractice regulations executed in the USA. In our study, the reason of the high percentage of students using rubber dam may be attributed to the close supervision of well-trained staff members in the different clinical sessions as well as the rules and regulation implemented by the colleges for the work in the undergraduate clinics.

In this study, a general belief among dental practitioners that patients dislike rubber dam usage was observed. However, this result is contradicted by studies concluding that rubber dam is an accepted element of dental care by patients. ${ }^{[6,22,23]}$ This result may be related to insufficient experience of the surveyed undergraduate student in dealing with the patients. This is supported by Whitworth et al. who found a great correlation between the negative practitioner attitude and patient behavior toward rubber dam. ${ }^{[12]}$ Furthermore, Stewardson and McHugh found that the experience of the dentist influences the patient's opinion. ${ }^{[6]}$

The percentage of students who did not use rubber dam for child patients in both schools was $88.77 \%$ this exceeded the $68 \%$ reported by Mala et al. ${ }^{[2]}$ This issue, however, needs to be considered from a pedodontic standpoint, probably in a future study focusing on this group of patients.

Most of the surveyed students in both colleges respond positively to the use of rubber dam for esthetic restoration either anterior or posterior. Terry explained the importance of rubber dam on the basis of technique sensitivity of resin composite. ${ }^{[24]} \mathrm{He}$ stated that isolation of the operative field is very important before the placement of esthetic restoration as contamination with saliva, blood, or crevicular fluid may adversely affect the material property or the bond strength.

The use of rubber dam for maxillary anterior Class $\mathrm{V}$ was the least percentage among the surveyed students. The students of Al-Farabi College use it more frequently than Buraidah, and the difference was statistically significant. This may be explained by sufficient isolation with cotton rolls due to the absence of major salivary glands at this area.

It is also noteworthy to mention that dental students may display more idealistic views about contemporary methodologies before graduation. With the progression of years of dental service, there might be some alterations in their views.

\section{CONCLUSIONS}

Under the limitation of this study, we can conclude that rubber dam application has a wide acceptance among underground students. However, we cannot depend completely on the result of the survey, but it is acceptable tool to give an indication of what will be the clinical practice in the near future.

\section{Financial support and sponsorship}

Nil.

\section{Conflicts of interest}

There are no conflicts of interest.

\section{REFERENCES}

1. European Society of Endodontology. Quality guidelines for endodontic treatment: Consensus report of the European Society of Endodontology. Int Endod J 2006;39:921-30.

2. Mala S, Lynch CD, Burke FM, Dummer PM. Attitudes of final year dental students to the use of rubber dam. Int Endod J 2009;42:632-8.

3. Abdulrab S, Al-Maweri S, Doumani M, Mourshed B, Alaizari N. Rubber dam: Attitudes and practices of senior dental students in Saudi Arabia. IOSR J Dent Med Sci 2016;15:79-83.

4. Iwatani K, Matsuo K, Kawase S, Wakimoto N, Taguchi A, Ogasawara T. Effects of open mouth and rubber dam on upper airway patency and breathing. Clin Oral Investig 2013;17:1295-9.

5. Ahmad IA. Rubber dam usage for endodontic treatment: A review. Int Endod J 2009;42:963-72.

6. Stewardson DA, McHugh ES. Patients' attitudes to rubber dam. Int Endod J 2002;35:812-9.

7. Gilbert GH, Litaker MS, Pihlstrom DJ, Amundson CW, Gordan VV; DPBRN Collaborative Group. Rubber dam use during routine operative dentistry procedures: Findings from the dental PBRN. Tex Dent J 2013;130:337-47. 


\section{Al-Sabri, et al.: Isolation in operative field}

8. Cohen S, Schwartz S. Endodontic complications and the law. J Endod 1987;13:191-7.

9. Udoye $\mathrm{CI}$, Jafarzadeh $\mathrm{H}$. Rubber dam use among a subpopulation of Nigerian dentists. J Oral Sci 2010;52:245-9.

10. Joynt RB, Davis EL, Schreier PH. Rubber dam usage among practicing dentists. Oper Dent 1989;14:176-81.

11. Al-Omari MA, Al-Dwairi ZN. Compliance with infection control programs in private dental clinics in Jordan. J Dent Educ 2005;69:693-8.

12. Whitworth JM, Seccombe GV, Shoker K, Steele JG. Use of rubber dam and irrigant selection in UK general dental practice. Int Endod J 2000;33:435-41.

13. Jenkins SM, Hayes SJ, Dummer PM. A study of endodontic treatment carried out in dental practice within the UK. Int Endod J 2001;34:16-22.

14. Feierabend SA, Matt J, Klaiber B. A comparison of conventional and new rubber dam systems in dental practice. Oper Dent 2011;36:243-50

15. Hill EE, Rubel BS. Do dental educators need to improve their approach to teaching rubber dam use? J Dent Educ 2008;72:1177-81.

16. Ryan $\mathrm{W}, \mathrm{O}^{\prime}$ Connel $\mathrm{A}$. The attitudes of undergraduate dental students to the use of the rubber dam. J Ir Dent Assoc 2007;53:87-91.
17. Going RE, Sawinski VJ. Parameters related to the use of the rubber dam. J Am Dent Assoc 1968;77:598-601.

18. Unal GC, Kaya BU, Tac AG, Kececi AD. Survey of attitudes, materials and methods preferred in root canal therapy by general dental practice in Turkey: Part 1. Eur J Dent 2012;6:376-84.

19. Peciuliene V, Rimkuviene J, Aleksejuniene J, Haapasalo M, Drukteinis S, Maneliene R. Technical aspects of endodontic treatment procedures among Lithuanian general dental practitioners. Stomatologija 2010;12:42-50.

20. Slaus G, Bottenberg P. A survey of endodontic practice amongst Flemish dentists. Int Endod J 2002;35:759-67.

21. Whitten BH, Gardiner DL, Jeansonne BG, Lemon RR. Current trends in endodontic treatment: Report of a national survey. J Am Dent Assoc 1996;127:1333-41.

22. Reuter JE. The isolation of teeth and the protection of the patient during endodontic treatment. Int Endod J 1983;16:173-81.

23. Jones CM, Reid JS. Patient and operator attitudes toward rubber dam. ASDC J Dent Child 1988;55:452-4.

24. Terry DA. An essential component to adhesive dentistry: The rubber dam. Pract Proced Aesthet Dent 2005;17:106, 108 